\title{
Synthetic Characterization of Cellulose from Moringa oleifera seeds and Potential Application in Water Purification
}

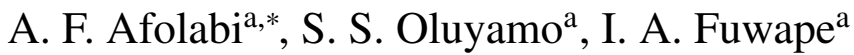 \\ ${ }^{a}$ Condensed Matter and Statistical Physics Research Unit, Department of Physics, The Federal University of Technology, P.M.B. 704, Akure, Nigeria
}

\begin{abstract}
The use of Moringa oleifera seeds for purifying water has been attempted locally in various forms without putting scientific potency of the material into consideration. The cellulose sample isolated from Moringa oleifera seed was characterized using X-ray diffraction (XRD), scanning electron microscopy (SEM) and fourier transform infrared spectroscopy (FTIR). The value of crystallinity index $\left(C_{I r}\right)$ from the XRD pattern is $63.1 \%$. The high degree of crystallinity obtained is attributed to the high percentage of crystallinity index, $C_{I r}$ (i.e. 63.1\%). The morphology revealed aggregates of conical and needle-like structure. The FTIR revealed $\mathrm{O}-\mathrm{H}$ stretching, $\mathrm{C}-\mathrm{H}$ stretching vibration and $\mathrm{C}=\mathrm{O}$ bond stretching functional groups. These characteristics are indicative of the potential of the material in water purification.
\end{abstract}

DOI:10.46481/jnsps.2021.206

Keywords: Cellulose, Crystallinity, Moringa oleifera, Morphology, Water purification

Article History :

Received: 22 April 2021

Received in revised form: 27 May 2021

Accepted for publication: 03 June 2021

Published: 29 August 2021

(C)2021 Journal of the Nigerian Society of Physical Sciences. All rights reserved. Communicated by: B. J. Falaye

\section{Introduction}

Water is a source of life and human existence depends to a large extend on its availability. Water is obtained from different sources such as rain, dam, river, stream, borehole, well and lake e.t.c. The importance of water cannot be over-emphasized in our daily living. It has a broad impact on health, food, energy, economy and also necessary for human survival. The level of purity of water utilized in daily life is very significant since it has a definite effect on human health. Likewise, water is an essential component of all living systems. The quality of drinking water has become a major concern since contaminants and toxic compounds are mostly accumulated in the body system thereby causing serious hazard to human health. Hence, there is a need

\footnotetext{
${ }^{*}$ Corresponding author tel. no: +2347030614850

Email address: agafolabi@gmail.com (A. F. Afolabi )
}

for water purification to afford access to potable water for human consumption. Imported chemicals for purifying water are expensive and have unfavorable effects on human health [1,2]. Therefore, there is a dire need to use locally sourced and environmentally friendly organic material for water purification.

Moringa oleifera is non-toxic and has an added favourable opportunity over the chemical purification of water due to the medicinal and therapeutics properties such as cholesterol lowering, anti-inflammatory, antiulcer, antioxidant, antidiabetic, antispasmodic, antibacterial, antihypertensive, antiepileptic, antidiabetic, antifungal activity, antitumor and antimicrobial properties [3-6]. Moringa has been discovered to be used in different health care products including body and hair conditioners and moisturizers.

Moringa oleifera is a plant material composed of lignin, hemicellulose and cellulose [7]. Cellulose has a degree of polymerization of about 10,000 insoluble polysaccharide which con- 
sist of linear chains of glucopyranose units linked by a $\beta-1,4$ glycosidic bond. The common formula is $\left(\mathrm{C}_{6} \mathrm{H}_{10} \mathrm{O}_{5}\right)_{n}$ [8]. Furthermore, cellulose is a prominent structural composition of the cell wall of different plants. Cellulose also exists in a broad diversity of class of living, such as algae, fungi, bacteria, and even in some sea animals such as tunicates.

A lot has been accomplished in the use of Moringa oleifera for water purification, creating general interest in the researcher of Moringa oleifera utilization. Despite the attractiveness of this research, several challenges remain unresolved in the effective use of Moringa oleifera. Some of the challenges are: Moringa oleifera seeds contain soluble organics that increase the residual organic carbon of the treated water which may serve as food for pathogens (microorganism that can cause harmful effect to the body system) and the large consumption of particles of Moringa oleifera seeds precipitate into the body could also pose health challenges to the body. In this research, all the soluble organics and particles in Moringa oleifera seeds which could pose health challenges to the body when consumed were eliminated during isolation of cellulose from Moringa oleifera seeds which give pure and refined sample. The aim of this research is to identify the intrinsic potential of the cellulose of Moringa oleifera seed for the purification of water.

\section{Materials and Methods}

\subsection{Materials}

The locally sourced organic material used in this research is moringa oleifera seed. It was removed from the shell, dried, grinded with a grinder and sieved to obtain fine particles. $\mathrm{Pu}-$ rification process was adopted to isolate cellulose and remove components that are not cellulose which include lignin, hemicelluloses, fats and inorganic contaminants.

Acetic acid, Sodium chlorite $\left(\mathrm{NaClO}_{2}\right)$ and Sodium hydroxide $(\mathrm{NaOH})$ were obtained from Pascal Scientific Ltd and used as analytical chemical reagents.

\subsection{Methods}

A liquor ratio of $15: 1(\mathrm{~V} / \mathrm{W})$ cooking condition was employed, the Moringa oleifera seed particles was pulped with $20 \%$ of $\mathrm{NaOH}$ at a temperature of $90^{\circ} \mathrm{C}$ for 1 hour 30 minutes. After digestion process, the cooked pulp was filtered, screened and cleaned by rinsing properly with water without alkali. The pulped was left in the oven at $105^{\circ} \mathrm{C}$ until the water was completely dried. $200 \mathrm{~mL}$ of hot water, $6 \mathrm{~g}$ of $\mathrm{NaClO}_{2}$ and $1.5 \mathrm{~mL}$ of acetic acid were mixed with $10 \mathrm{~g}$ of bone dried sample of pulp in a titration flask. At $70^{\circ} \mathrm{C}$, the mixture was placed in the water bath and heated for 30 minutes. Another $6 \mathrm{~g}$ of $\mathrm{NaClO}_{2}$ and $1.5 \mathrm{~mL}$ of acetic acid were mixed and included, submitted to heat for next 30 minutes before putting the water bath power off. The sample remained in the water bath for 24 hours. After digestion, it was filtered and cleaned by rinsing properly with water until the chlorine and the acid were washed away. The sample acquired was left in the oven at $105^{\circ} \mathrm{C}$ until the water was completely dried to obtain the cellulose.

\section{Characterization}

The crystallinity index of the isolated cellulose from Moringa olienfera seeds was obtained using a Philips PW diffractometer with $\mathrm{Cu}-\mathrm{K} \alpha$ monochromator at voltage of $15 \mathrm{kV}$, scanned at wavelength $\lambda=1.54 \AA$ with $2 \theta$ angle range from $5^{\circ}$ to $90^{\circ}$. The scanning electron microscope which was used to determine surface morphology was achieved using $15 \mathrm{kV}$ accelerated voltage of JEOL/EO JSM-6390 and has a resolution up to $100 \mu \mathrm{m}$. The variation in functional groups was determined by fourier transform infrared (FTIR) Spectrophotometer induced by various treatments within a wavelength range of $700-4000 \mathrm{~cm}^{-1}$.

\subsection{Theoretical Background}

The Interplanar spacing (d-spacing) was obtained as in equation $(1)[9,10]$

$$
d=\frac{n \lambda}{2 \sin \theta}
$$

where, the interplanar spacing of the crystal is $d$, order of reflection is $\mathrm{n}$, wavelength of the incident $\mathrm{X}$-ray is $\lambda$ and angle of incidence is $\theta$.

The crystallinity index was calculated as following equation (2) $[11,12]$

$$
C_{I r}=\frac{I_{200}-I_{a m}}{I_{200}} \times 100
$$

where, highest peak intensity of the crystalline fractions is $I_{200}$ and low intensity peak of the amorphous region is $I_{a m}$.

The crystallite size $(L)$ was calculated using Scherrer's equation [13]

$$
L=\frac{K \times \lambda}{B \times \operatorname{Sin} \theta}
$$

where, constant value given as 0.91 is $K$, wavelength of the incident $\mathrm{X}$-rays is $\lambda$, Bragg's angle $\left(^{\circ}\right)$ is $\theta$, and intensity of the full width at half maximum (FWHM) proportional to a high intensity peak of the diffraction plane is $B$.

\section{Results and Discussions}

\subsection{X-Ray Diffraction (XRD)}

XRD pattern of isolated cellulose from Moringa oleifera seeds revealed crystalline characteristics peaks at $2 \theta=14.39^{\circ}$, $15.33^{\circ}, 22.47^{\circ}$ and $34.50^{\circ}$, indicating the crystal structure of cellulose I with allomorph cellulose I $\beta$ (monoclinic) [14]. The crystalline peaks indicate that the crystal structure is attributed to planes (11̄0), (110), (200) and (004) respectively. It shows that the occurrence of intra and inter-molecular hydrogen bonding in the cellulose through hydroxyl group can ignite the arrangement of crystal order in the cellulose [15]. From the isolated cellulose, the peaks $14.39^{\circ}$ and $15.33^{\circ}$ were observed around $15^{\circ}$ and the peak $15.33^{\circ}$ was broad due to the amorphous nature of the material used [16,17]. The isolated cellulose shows prominent peak at $22.47^{\circ}$ which exhibited higher crystallinity because of the efficient elimination of the amorphous parts. The value of crystallinity index $\left(C_{I r}\right)$ is $63.1 \%$, 


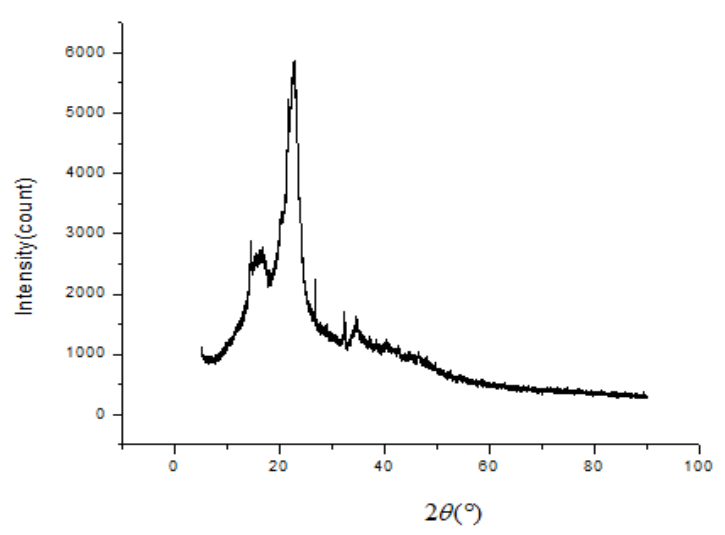

Figure 1. X-ray diffractogram of isolated cellulose from Moringa oleifera seeds

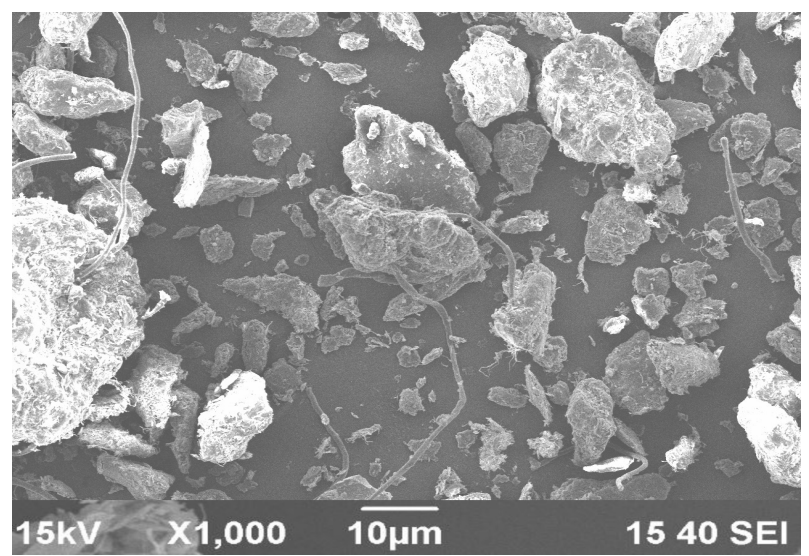

Figure 2. Scanning electron micrograph of isolated cellulose from Moringa oleifera seeds

Crystallite size $(\mathrm{L})$ is $1.95 \mathrm{~nm}$, d-spacing is $3.9 \AA$ and FWHM is 0.07331 . Since the proportion of crystallinity index is high, then the degree of crystallinity is justified to be high. The high proportion of crystallinity index is ascribed to removal of some of the amorphous constituents and rearrangement of the crystalline regions into a more ordered structure [9].

\subsection{Scanning Electron Micrograph (SEM)}

The morphological features of the cellulose isolated from Moringa oleifera seeds are shown in Figure 2. The surface morphology showed that the particles have conical and needle-like feature. The isolated cellulose has an average length and diameter of $.2 \mu \mathrm{m}$ and $88.9 \mu \mathrm{m}$ respectively. It was disjointed from one another, indicating the total elimination of hemicelluloses and lignin. This is similar to previous researches on the cellulose from oil palm empty fruits bunch extraction and characterization and cellulose nanocrystals from corncob extraction and characterization for application as reinforcing agent nanocomposites [12,18].

\subsection{Fourier Transform Infrared (FTIR) Spectroscopy}

Figure 3 shows the Fourier transform infrared spectra of the isolated cellulose. Some important functional groups oc-

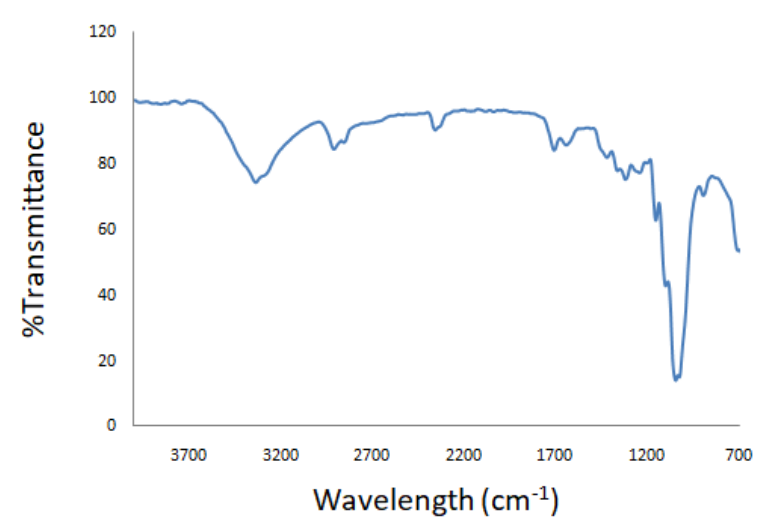

Figure 3. Fourier transform infrared (FTIR) spectra of isolated cellulose from Moringa oleifera seeds

cupied by the cellulose which however revealed basic potentials of the material for water purification are highlighted. The spectra showed wide band centered at $3311 \mathrm{~cm}^{-1}$ appointed to $\mathrm{O}-\mathrm{H}$ stretching. This functional group commonly present in the cellulose. There is also a feature in this region from the $\mathrm{N}$ $\mathrm{H}$ stretching of amide group which reect the cationic tendency of the cellulose. This is similar to the result of characterization and use of moringa oleifera seeds as a biosorbent for removing metal ions from aqueous effluents [19].

At $2887 \mathrm{~cm}^{-1}$, there exist spectra of characteristics of C$\mathrm{H}$ stretching vibration. In the region between $1687 \mathrm{~cm}^{-1}$ and $1308 \mathrm{~cm}^{-1}$ there are bands appointed to $\mathrm{C}=\mathrm{O}$ bond stretching. The carbonyl group appears in the structures and there is a band at $1610 \mathrm{~cm}^{-1}$ accompanied with the amide group. The presence of hydroxyl, carbonyl and amine groups are responsible for the coagulative capacity in water purification $[20,21]$.

\section{Conclusion}

The XRD determines the high percentage of crystallinity index of the cellulose and the degree of crystallinity was found to be high. The XRD pattern also revealed that the crystal structure is cellulose I with allomorph cellulose I $\beta$ (monoclinic). The characterization of isolated cellulose using fourier transform infrared spectroscopy (FTIR) revealed O-H stretching, $\mathrm{C}-\mathrm{H}$ stretching vibration and $\mathrm{C}=\mathrm{O}$ bond stretching functional groups. The presence of hydroxyl, carbonyl and amine groups are responsible for the coagulative capacity in water purification.

\section{Acknowledgments}

The authors gratefully appreciate Dr. Ige, O.O. and Dr. Alo, F.I. of the Department of Material Science and Engineering, Obafemi Awolowo University Ile-ife, Osun State, Nigeria for their effort in the analysis of the samples. Dr. Adekoya Mathew, Mr. Olasoji, M.O. and the Department of Materials and Metallurgical Engineering of the Federal University of Technology, 
Akure, Nigeria are also appreciated for their support during the period of the research.

\section{References}

[1] U. A. Abdulwahab, S. S. Sumaila, W. M. Manja, B. Opoku \& J. Ibrahim "Assessment on the potential of moringa oleifera seed extract in the clarification of turbid surface water", International Journal of Scientific and Research Publications 6 (2016) 564

[2] I. R. Hendrawati, E. Rohaeti, H. Effendi \& L. K. Darusman "The use of moringa oleifera seed powder as coagulant to improve the quality of wastewater and ground Water", IOP Conf. Series: Earth and Environmental Science 31 (2016) 1, doi: 10.88/1755-1315/1/012033.

[3] F. K. Amagloh \& A. Benang "Effectiveness of Moringa oleifera seed as coagulant for water purication", African Journal of Agricultural Research 4 (2009) 119

[4] N. Matinise, X. G. Fuku, K. Kaviyarasu, N. Mayadwa \& M. Maaza “ ZnO nanoparticles via Moringa oleifera green synthesis: Physical properties and mechanism of formation", Applied Surface Science 406 (2017) 339, doi:10.1016/j.apsusc.2017.01.219.

[5] R. Paliwal, V. Sharma \& S. Pracheta "Anti-nephrotoxic effect of administration of Moringa oleifera Lam in amelioration of DMBA-induced renal carcinogenesis in swiss albino mice", Biology and Medicine 3 (2011) 27.

[6] F. T. Thema, P. Beukes, A. Gurib-Fakim \& M. Maaza "Green synthesis of Monteponite $\mathrm{CdO}$ nanoparticles by Agathosma betulina natural extract", Journal of Alloys Compound 646 (2015) 1043, doi: 10.1016/j.jallcom.2015.05.279.

[7] A. M. Mansora, J. S. Lima, F. N. Anib, H. Hashima \& W. S. Hoa "Characteristics of Cellulose, Hemicellulose and Lignin of MD2 Pineapple Biomass", Chemical Engineering Transactions 79 (2019) 79.

[8] B. W. Chieng, H. S. Lee, A. N. Ibrahim, Y. Y. Then \& Y. Y. Loo "Isolation and characterization of cellulose nanocrystals from oil palm mesocarp fiber", Polymers 8 (2017) 355, doi: 10.3390/polym9080355.

[9] M. A. Adekoya, S. S. Oluyamo, O. O. Oluwasina \& A. I. Popoola "Structural characterization and solid state properties of thermal insulating cellulose materials of different size classifications", Bioresources 13 (2018) 906-917, doi: 10.15376/biores.13.1.906-917.

[10] U. J. Kim \& S. H. Eom, M. Wada "Thermal decomposition of native cellulose: influence on crystallite size", Polymer Degradation Stability 95 (2010) 778, doi: 10.1016/j.polymdegradstab.2010.02.009.
[11] A. Mandal \& D. Chakrabarty "Isolation of nanocellulose from waste sugarcane baggase and its characterization", Carbohydrate Polymers 86 (2011) 1291, doi: 10.1016/j.carbpol.2011.06.030.

[12] M. S. Nazir, B. A. Wahjoedi, A. W. Yussof \& M. A. Abdullah "Ecofriendly extraction and characterization of cellulose from oil palm empty fruit bunches", BioResources 2 (2013) 2161, doi:10.15376/biores.8.21612172.

[13] M. Poletto, H. L. O. Júnior \& A. J. Zattera "Native Cellulose: structure, characterization and thermal Properties", Materials 7 (2014) 6105, doi: 10.3390/ma7096105.

[14] N. A. Rosli, I. Ahmad \& I. Abdullah "Isolation and characterization of cellulose nanocrystals from Agave Augustifolia fibre", BioResources 2 (2013) 1893, doi: 10.15376/biores.8.2.1893-1908.

[15] M. Asrofi, H. Abral, A. Kasim \& A. Pratoto "XRD and FTIR studies of nanocrystalline cellulose from water hyacinth (Eichornia crassipes) fiber", Journal of Metastable and Nanocrystalline Materials 29 (2017) 9, doi: 10.4028/www.scientific.net/JMNM.29.9.

[16] C. Borsoi, H. L. Ornaghi, L. C. Scienza, A. J. Zattera \& C. A. Ferreira "Isolation and characterisation of cellulose nanowhiskers from microcrystalline cellulose using mechanical processing", Polymers \& Polymer Composites 25 (2017) 563, doi: 10.1177/096739111702500801.

[17] K. Subramanian, S. P. Kumar, P. Jeyapal \& N. Venkatesh "Characterization of lingo-cellulosic seed fibre from Wrightia tinctoria plant for textile applications-An exploratory investigation", European Polymer Journal 41 (2005) 853, doi: 10.1016/j.eurpolymj.2004.10.037.

[18] H. A. Silverio, W. P. F. Neto, N. O. Dantas \& D. Pasquini "Extraction and characterization of cellulose nanocrystals from corncob for application as reinforcing agent in nanocomposites", Industrial Crops and Products 44 (2013) 427, doi: 10.1016/j.indcrop.2012.10.014.

[19] C. Araujo, L. S. Almeida, V. N. Alves \& R. Assuncao "Characterization and use of moringa oleifera seeds as a biosorbent for removing metal ions from aqueous effluents", Water Science and Technology 62 (2010) 2198, doi: 10.2166/wst.2010.419.

[20] L. A. Abdel-Rahman, A. M. Abu-Dief, M. A. Abd- El Sayed \& M. M. Zikry "Nano Sized Moringa oleifera an Effective Strategy for $\mathrm{Pb}(\mathrm{II})$ ions Removal from Aqueous Solution", Chemistry and Materials Research 8 (2016) 8 .

[21] M. A. Idris, M. S. Jami, A. M. Hammed \& P. Jamal "Moringa oleifera seed extract: A review on its environmental applications", International Journal of Applied Environmental Sciences 11 (2016) 1469. 